\title{
Universiteit
}

Leiden

The Netherlands

\section{Patient self-management of oral anticoagulant care vs. management by specialized anticoagulation clinics: positive effects on quality of life} Gadisseur, A.P.A.; Kaptein, A.A.; Breukink-Engbers, W.G.M.; Meer, F.J.M. van der; Rosendaal, F.R.

\section{Citation}

Gadisseur, A. P. A., Kaptein, A. A., Breukink-Engbers, W. G. M., Meer, F. J. M. van der, \& Rosendaal, F. R. (2004). Patient self-management of oral anticoagulant care vs.

management by specialized anticoagulation clinics: positive effects on quality of life. Journal Of Thrombosis And Haemostasis, 2(4), 584-591. Retrieved from https://hdl.handle.net/1887/5092

Version: $\quad$ Not Applicable (or Unknown)

License:

Downloaded from: https://hdl.handle.net/1887/5092

Note: To cite this publication please use the final published version (if applicable). 


\title{
Patient self-management of oral anticoagulant care vs. management by specialized anticoagulation clinics: positive effects on quality of life
}

\author{
A. P. A. GADISSEUR, ${ }^{*}{ }^{* *}$ A. A. KAPTEIN, + W. G. M. BREUKINK-ENGBERS, F. J. M. VAN DER MEER*§ \\ and F. R. ROSENDAAL* $\dagger$ \\ *Department of Hematology/Hemostasis and Thrombosis Research Center, †Department of Clinical Epidemiology and $\ddagger$ Department of Medical \\ Psychology, Leiden University Medical Center (LUMC), Leiden, the Netherlands; §Leiden Anticoagulation Clinic, Leiden, the Netherlands; \\ $\uparrow$ Oost-Gelderland Anticoagulation Clinic, Lichtenvoorde, the Netherlands; and **Department of Hematology, Antwerp University Hospital, \\ Antwerp, Belgium
}

To cite this article: Gadisseur APA, Kaptein AA, Breukink-Engbers WGM, van der Meer FJM, Rosendaal FR. Patient self-management of oral anticoagulant care vs. management by specialized anticoagulation clinics: positive effects on quality of life. J Thromb Haemost 2004; 2: 584-91.

Summary. Background: Oral anticoagulant therapy (OAT) implies frequent blood checks and dose changes to prevent thromboembolic or hemorrhagic complications. This may interfere with patients' social and working circumstances in addition to the possible stress caused by the condition necessitating this treatment. We studied whether patient selfmanagement could be a way to improve quality of life in these patients. Methods: Within a multicenter randomized study performed by two Dutch anticoagulation clinics, designed to study the effect on treatment quality (time within target range) of different modalities of patient self-management, we looked at the effect of increased patient education $(n=28)$, self-monitoring of the International Normalized Ratio (INR) $(n=47)$ and full patient self-management (INR monitoring and dosing of the OAT) $(n=41)$ on the quality of life of the patients. This was done with the aid of a written questionnaire (32 questions, minimum score $=1$, maximum score $=6$ ) at baseline $(n=163)$, and after 26 weeks $(n=118)$. We compared the results after 26 weeks with those at baseline, as well as between groups. Results: General treatment satisfaction was already high under routine care (5.11 on a scale of 1-6) and increased

Correspondence: F. R. Rosendaal, Department of Clinical Epidemiology, C-9-P, Leiden University Medical Center (LUMC), Albinusdreef 2, Post Box 9600, 2300 RC Leiden, the Netherlands. Tel.: + 3171526 4037; fax: + 3171526 6994; e-mail: f.r.rosendaal@, lumc.nl

A.P.A.G. and W.G.M.B-E. were the principal investigators and headed the teams in Leiden and Lichtenvoorde responsible for carrying out the study. A.A.K. was invaluable for expert interpretation and analysis of the QoL data. F.J.M.v..M. and F.R.R. provided guidance on the design and analysis.

Received 9 September 2003, accepted 9 December 2003 further through self-monitoring of the INR $(+0.19)$ and full self-management $(+0.32)$. Distress $(-0.44)$, perceived daily hassles $(-0.31)$ and strain on the social network $(-0.21)$ were reduced through full self-management. Improved patient education was associated with increased distress $(+0.33)$ and perceived daily hassles $(+0.23)$. Comparison at 26 weeks between groups showed similar improvements on these outcomes for self-monitoring and self-management vs. routine care after education.

Keywords: oral anticoagulation, quality of life, self-management

\section{Introduction}

Oral anticoagulant therapy (OAT) with coumarin drugs is of vital importance in the prophylaxis and treatment of thrombosis. The efficacy and relative safety of oral anticoagulants have been proven extensively by clinical studies and different therapeutic International Normalized Ratio (INR) target ranges have been set for OAT in various indications [1]. Strict control of the INR within the target INR range is required to ensure good efficacy of treatment, minimizing the rate of thrombotic and bleeding complications. Due to the many factors that influence OAT, frequent INR measurements and dose adjustments are necessary.

In the Netherlands a national network of specialized anticoagulation clinics is responsible for the management of OAT [2]. These anticoagulation clinics collect blood samples, perform the prothrombin time (PT)/INR measurements, gather information on intercurrent diseases and co-medication, establish the dosage of the OAT and provide advice for patients and other physicians. The development of these specialized anticoagulation clinics has led to improved management of 
OAT [2]. Frequent monitoring of the PT/INR values, however, continues to be an important aspect of treatment, which may have physical, psychological, social and financial consequences for both patient and the healthcare system. This need for frequent monitoring may interfere with patients' social and working life, in addition to the possible stress caused by the treatment itself and the condition necessitating this treatment.

The development of hand-held PT/INR measurement devices, which determine the prothrombin time from capillary whole blood, has led to the development of self-management of OAT (self-measurement of INR values and self-dosing of coumarin medication) by patients. The potential advantages of patient self-management include improved convenience for patients, with less interference with their lifestyle, better compliance and more frequent monitoring, as well as improved quality of OAT resulting in less thromboembolic and hemorrhagic complications [3]. Improvement of the quality of anticoagulant care through patient self-management has been suggested by several studies comparing this new treatment modality with the existing system, be it anticoagulant care through a diversity of physicians [4-11] (general practitioners, medical specialists, laboratory physicians) or through specialized anticoagulation clinics as in the Netherlands $[12,13]$. In these studies the number of INR checks within the target range and/or the estimated time that the INR fell within this range was increased through patient self-management.

In recent years Quality of Life (QoL) has become an important concept in medical care, linking clinical variables with health-related quality of life [14]. Quality of life encompasses the effects of an illness and its treatment on the patient, as perceived by the patient. Self-management of (chronic) illness represents a major new development in medical care. Benefits of self-management on quality of life have been shown in, for example, asthma [15] and diabetes mellitus [16,17].

Sawicki et al. noted an improvement in several treatmentrelated areas of quality of life through patient self-management in comparison with routine anticoagulant care through family physicians [4]. Quality of life was assessed at baseline and at end of study with the aid of a quality of life questionnaire that the authors developed. Cromheeke et al. used the same questionnaire in a study in the Netherlands comparing anticoagulant care through specialized anticoagulation clinics with patient self-management in a cross-over study and also noted an improvement in treatment-related quality of life [12], indicated by an increase in general treatment satisfaction and a decrease in perceived daily hassles and distress. Kulinna et al. found an improvement in treatment quality and quality of life through self-monitoring of the INR (no full self-management) [13]. They did not use the Sawicki questionnaire. Independence and better organization of vacation and spare time were the most frequently mentioned advantages of the new method.

Our study aimed to assess the effects on oral anticoagulant treatment-related quality of life through different treatment modalities: routine anticoagulant care through specialized anticoagulation clinics; self-monitoring of the INR by the patients but dosing by specialized anticoagulation clinics; and full self-management of the OAT by patients. Because self-management, by definition, includes extensive patient education about their condition and its treatment, which may affect quality of life rather than the self-management itself, we also investigated the effect of increased patient education on patient QoL. Previously, we reported the results concerning the number of INR checks and the time in target INR range in this randomized controlled trial, comparing patient self-management of oral anticoagulant therapy with routine care delivered by specialized anticoagulation clinics in the Netherlands [14].

\section{Materials and methods}

\section{Patients}

In this study performed by two Dutch anticoagulation clinics which together are responsible for the oral anticoagulant treatment of around 18000 patients per year, patients were selected by computer on the basis of the following criteria: indication for long-term oral anticoagulant therapy with phenprocoumon or acenocoumarol, at least 3 months of OAT experience, and an age range of 18-75 years. The two anticoagulation clinics represent different patient populations. The Leiden anticoagulation clinic is in the west of the Netherlands and essentially represents an urban environment, while the Oost-Gelderland anticoagulation clinic is located in the east of the country in a predominantly rural area.

Patients who were willing to participate in the study were invited to three training sessions. After successful training the patients were randomized into three treatment groups: 'weekly self-measurement of the INR' (group A); 'weekly self-measurement of the INR and self-management of the OAT' (group B); or 'routine care in educated patients' (group C). All patients included in the study groups were followed for 26 weeks. A schematic overview of the study design and final patient numbers is given in Fig. 1. In total 720 patients were contacted for participation in training, of whom 184 consented to participate, but of these four patients were later unavailable. The quality of life study was carried out within the confines of a larger study looking at the quality of anticaogulant treatment. In this study a large control group (group D) was included in a Zelen design, as can be seen in Fig. 1 .

A quality of life questionnaire was distributed to all patients invited to the training sessions $(n=180)$ at the start of the first training session, and again at the end of the follow-up (26 weeks). The questionnaire at baseline was intended to measure patient concerns under the routine anticoagulant care system managed by the anticoagulation clinics, while the (identical) end-of-study questionnaire was meant to measure the impact of self-monitoring of the INR, full patient selfmanagement of OAT, and possibly of increased patient education (see Quality of life questionnaire).

The structured training program consisted of three weekly sessions of 90-120 min in which the patients received information about the coagulation system and oral anticoagulant 


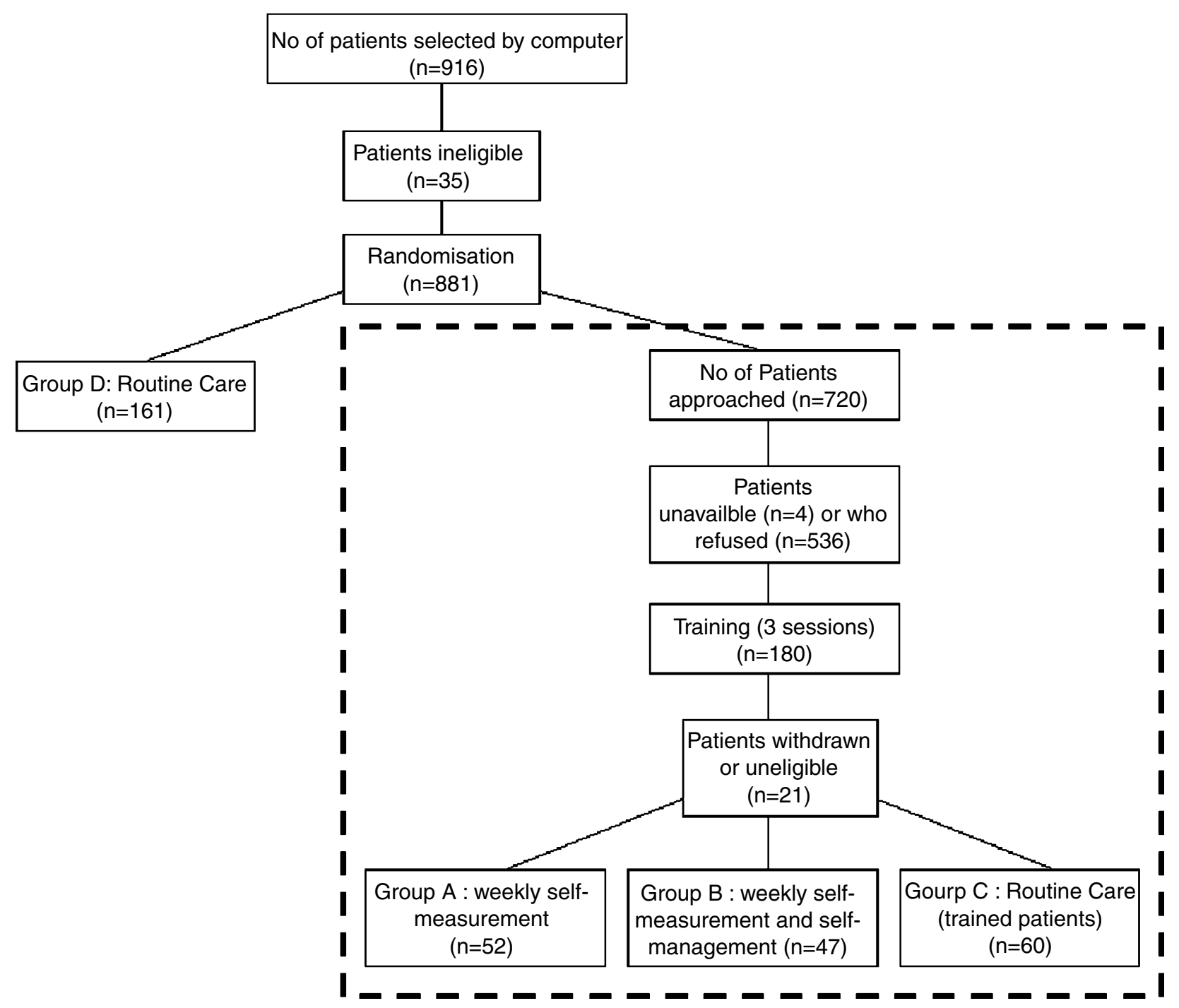

Fig. 1. Design and patient numbers involved in the study comparing patient self-management of oral anticoagulant therapy with routine anticoagulant care delivered by specialized anticoagulation clinics. The area within the dotted line denotes the limits of the quality of life study.

treatment and the influences thereon, were trained in working with the CoaguChek $^{\circledR}$ device, and were instructed on self-dosing of oral anticoagulant therapy with phenprocoumon and acenocoumarol. Training was done by specialized teams present in both anticoagulation clinics, consisting of physicians and nurses, in groups of four to five patients.

\section{Treatment modalities}

In this study the effects on quality of life of different treatment modalities were assessed.

Self-monitoring of the INR (group A) After going through the training program the patients performed the measurement of the INR at home on a weekly basis with the aid of a handheld coagulometer (CoaguChek ${ }^{\circledR}$; Roche Diagnostics, Mannheim, Germany) and relayed the result together with relevant information to the anticoagulation clinics. Dosing of the OAT was done by physicians at the anticoagulation clinic based upon the INR value and the relayed information; the next day the patients received a new dosing schedule for their anticoagulant medication by mail.

Patient self-management of $O A T$ (group B) After going through the training program the patients performed the measurement of the INR at home on a weekly basis with the aid of a hand-held coagulometer (CoaguChek ${ }^{\circledR}$; Roche Diagnostics) and were themselves responsible for the dosing of the anticoagulant medication. During the follow-up of the study the INR results and dosing schedules were relayed to the anticoagulation clinics as a safety measure. Corrections were proposed by the anticoagulation clinics in case of clear mistakes.

Increased patient education in routine care (group C) A group of patients were randomized to return to 'routine care' after having received the training for self-management of OAT. In the existing routine care system the patients 
come to the specialized anticoagulation clinics, at intervals determined by the stability of their INR values, where they are seen by skilled nurses and a venepuncture is performed. Dosing of the OAT is done by physicians based upon the INR value, the dosage history and information about changes in medication, illness, bleeding complications and other relevant information. New dosing schedules are forwarded to the patients by post (next-day delivery).

\section{Quality of life questionnaire}

The questionnaire used in the assessment of quality of life was developed by Sawicki and coworkers in patients receiving oral anticoagulation, and validated in their multicenter study comparing patient self-management with conventional anticoagulant care in Germany [4]. In Germany anticoagulant therapy is conventionally managed by general practitioners. The questionnaire was developed using the "clinical impact method' in which items are selected from a larger pool of statements based upon the importance given to them by the patients [18]. The resulting questionnaire mirrored the most important concerns of the patients regarding the defined condition or treatment.

The questionnaire consisted of 32 items covering five treatment-related topics: general treatment satisfaction, selfefficacy, strained social network, daily hassles, and distress. Self-efficacy pertains to the patient's belief in being able to perform self-care activities. In modern clinical health psychology self-efficacy has been shown to predict preventive health behavior and illness behavior [19]. Daily hassles are minor stressful events that add to the burden of having to cope with a chronic medical condition. Patients had to grade the degree to which the different statements were applicable to their individual situation, with a minimum score of 1 (total disagreement) to a maximum score of 6 (total agreement). Groups of individual statements were combined into five topics, leading to a mean score from 1 to 6 for the different topics. Improved quality of life was indicated by rising scores for the topics of self-efficacy and general treatment satisfaction, and by diminishing scores for the topics of daily hassles, distress, and strains on the social network.

The questionnaire was translated from German into Dutch and marginally adapted where necessary to make it compatible to the situation in the Netherlands where anticoagulant care is routinely handled by specialized anticoagulation clinics. The structure of the original questionnaire was preserved, and the questions were listed in the same order. Independently of our study the same questionnaire, but another translation, has been used and validated in another study assessing the quality of life and therapeutic quality of patient self-management of oral anticoagulation in the Dutch situation [12].

\section{Statistical analysis}

Results are presented as mean scores per treatment-related topic with standard deviations (SD). We compared results at
26 weeks with baseline, as well as between groups at 26 weeks. Paired samples $t$-test was used to compare scores between baseline and end of study within the same patient group. Independent samples $t$-test was used to compare between different patient groups. Cronbach $\alpha$ was calculated to give an indication of internal reliability of the five dimensions of the questionnaire.

\section{Results}

One hundred and sixty three patients returned the questionnaire at baseline, and 118 patients returned the questionnaire at the end of the study. One hundred and sixteen patients returned both the baseline questionnaire and the end-of-study questionnaire: 47 patients who performed weekly INR measurements with the CoaguChe ${ }^{\mathrm{k} \circledast}$ device, 41 patients on patient selfmanagement of OAT, and 28 patients in the 'routine care in educated patients' group. All analyses are restricted to patients who provided information at baseline and at 26 weeks. Patient characteristics are shown in Table 1.

At baseline the QoL questionnaire provided a picture of the concerns of the patients under the routine care system (Table 2). Cronbach $\alpha$ values varied from 0.53 to 0.74 depending on the topic. The quality of life scores are given on a scale of 1-6. The system of specialized anticoagulation clinics seems to result in a high general treatment satisfaction (score $=5.11, \mathrm{SD}=0.91$ ) while giving rise to a moderate degree of daily hassles (score $=1.71, \mathrm{SD}=0.64$ ), distress (score $=2.05, \mathrm{SD}=0.81$ ) and straining of the social network (score $=1.46, \quad \mathrm{SD}=0.62)$. No differences were found between the two participating anticoagulation clinics. There were no striking differences between the sexes, although women had a higher score for distress than men $(\delta=0.31$, $P=0.04)$. Daily hassles were scored higher by younger age groups, especially below the age of $50(\delta=+0.24, P=0.04)$, as was the element of distress $(\delta=+0.34, P=0.02)$, which below the age of 40 increased even further $(\delta=+0.70$, $P=0.001)$.

At the end of the study increased patient education without self-management (group C) resulted in a trend towards a slight decrease in general treatment satisfaction, and in an increase in distress $(\delta=+0.33, P=0.03)$ and strain on the social network $(\delta=+0.21, P=0.02$ ) (Table 3).

The patients who monitored their INR values at home without self-dosing (group A) registered a trend towards an increase in their general treatment satisfaction $(\delta=+0.19$, $P=0.10)$ and an expected increase in their feeling of selfefficacy $(\delta=+0.31, P<0.01)$. There was little movement against baseline in the other treatment-related topics registered (Table 4).

The most important changes were seen in full patient selfmanagement of the OAT (group B). This mode of treatment led to a clear increase $(\delta=+0.49, P=0.01)$ in general treatment satisfaction (score $=5.55, \mathrm{SD}=0.63$ ) and the feeling of self-efficacy $(\delta=+0.32, P=0.014)$, and a significant decrease in the perception of daily hassles $(\delta=-0.31$, 
Table 1 Patient characteristics

\begin{tabular}{|c|c|c|c|c|}
\hline & $\begin{array}{l}\text { Baseline } \\
(n=163)\end{array}$ & $\begin{array}{l}\text { Group A: } \\
\text { self-measurement } \\
(n=47)^{*}\end{array}$ & $\begin{array}{l}\text { Group B: } \\
\text { self-management } \\
(n=41)^{*}\end{array}$ & $\begin{array}{l}\text { Group C: increased } \\
\text { patient education } \\
(n=28)^{*}\end{array}$ \\
\hline Age in years (range) & $58.1(21-75)$ & $54.8(24-75)$ & $53.9(24-75)$ & $59.8(21-73)$ \\
\hline Male/female ratio & $115 / 37$ & $38 / 9$ & $31 / 10$ & $20 / 8$ \\
\hline \multicolumn{5}{|l|}{ Indication for anticoagulation } \\
\hline DVT/PE/venousTE & $43(26.4 \%)$ & $11(23.4 \%)$ & $14(34.2 \%)$ & $7(25.0 \%)$ \\
\hline Arterial TE & $4(2.5 \%)$ & $1(2.1 \%)$ & $1(2.4 \%)$ & $1(3.6 \%)$ \\
\hline Atrial fibrillation & $26(15.9 \%)$ & $5(10.6 \%)$ & $7(17.1 \%)$ & $5(17.9 \%)$ \\
\hline Artificial heart valves & $34(20.9 \%)$ & $12(25.5 \%)$ & $5(12.2 \%)$ & $6(21.4 \%)$ \\
\hline Cardiovascular prophylaxis & $34(20.9 \%)$ & $12(25.5 \%)$ & $8(19.5 \%)$ & $5(17.9 \%)$ \\
\hline Cerebrovascular prophylaxis & $2(1.2 \%)$ & - & $1(2.4 \%)$ & - \\
\hline Vascular prosthesis & $15(9.2 \%)$ & $4(8.5 \%)$ & $3(7.3 \%)$ & $4(14.3 \%)$ \\
\hline Thrombophilia & $5(3.1 \%)$ & $2(4.3 \%)$ & $2(4.9 \%)$ & - \\
\hline \multicolumn{5}{|l|}{ Anticoagulant } \\
\hline Fenprocoumon & $119(73.0 \%)$ & $30(63.8 \%)$ & $26(63.4 \%)$ & $23(82.1 \%)$ \\
\hline Acenocoumarol & $44(27.0 \%)$ & $17(36.2 \%)$ & $15(36.6 \%)$ & $5(17.9 \%)$ \\
\hline \multicolumn{5}{|l|}{ Target INR } \\
\hline $2.5-3.5$ & $78(47.9 \%)$ & $22(46.8 \%)$ & $26(63.4 \%)$ & $10(35.7 \%)$ \\
\hline $3.0-4.0$ & $85(52.1 \%)$ & $25(53.2 \%)$ & $15(36.6 \%)$ & $18(54.3 \%)$ \\
\hline \multicolumn{5}{|l|}{ Quality of treatment $\dagger$} \\
\hline$\%$ INR checks in range $(95 \% \mathrm{CI})$ & $58.7(55.0,62.4)$ & $63.9(59.8,68.0)$ & $66.3(61.0,71.5)$ & $61.3(55.4,67.1)$ \\
\hline$\%$ time in range $(95 \% \mathrm{CI})$ & $63.5(59.7,67.3)$ & $66.9(62.7,71.0)$ & $68.6(63.7,73.6)$ & $67.9(62.9,73.0)$ \\
\hline & $\begin{array}{l}\text { All patients }(n=163) \\
\text { mean }(S D)\end{array}$ & $\begin{array}{l}\text { Leiden antic } \\
\text { clinic }(n=7 \\
\text { mean }(\mathrm{SD})\end{array}$ & tion & $\begin{array}{l}\text { lerland } \\
\text { lation clinic }(n=92) \\
\text { ) }\end{array}$ \\
\hline Daily hassles & $1.71(0.64)$ & $1.62(0.63)$ & & \\
\hline Self-efficacy & $5.03(0.88)$ & $5.04(0.83)$ & & \\
\hline General treatment satisfaction & $5.11(0.91)$ & $5.09(0.90)$ & & \\
\hline Distress & $2.05(0.81)$ & $2.17(0.87)$ & & \\
\hline Strained social network & $1.46(0.62)$ & $1.53(0.60)$ & & \\
\hline
\end{tabular}

Minimum score $=1$, maximum score $=6$. The results are given for all patients and stratified for the different anticoagulation clinics.

Table 3 Effect of increased patient education (group C)

\begin{tabular}{llll}
\hline & $\begin{array}{l}\text { Baseline }(n=28) \\
\text { mean (SD) }\end{array}$ & $\begin{array}{l}\text { Routine care system after } \\
\text { increased patient education }(n=28) \\
\text { mean (SD) }\end{array}$ & $\begin{array}{l}\text { Difference against baseline } \\
\text { mean }(P)^{*}\end{array}$ \\
\hline Daily hassles & $1.71(0.54)$ & $1.94(0.67)$ & $+0.23(P=0.117)$ \\
Self-efficacy & $5.05(0.82)$ & $5.07(0.84)$ & $+0.02(P=0.94)$ \\
General treatment satisfaction & $5.13(0.85)$ & $4.90(0.89)$ & $-0.23(P=0.21)$ \\
Distress & $1.95(0.70)$ & $2.29(1.05)$ & $+0.33(P=0.03)$ \\
Strained social network & $1.44(0.49)$ & $1.65(0.69)$ & $+0.21(P=0.02)$
\end{tabular}

Outcome of the questionnaire concerning five treatment-related topics, at baseline and at the end of the study period. Baseline score reflects the conventional system of oral anticoagulant care through specialized anticoagulation clinics. Minimum score $=1$, maximum score $=6$. ${ }^{*}$ Paired samples $t$-test on the 28 patients with both baseline and end-of-study questionnaire available.

$P<0.01)$ and distress $(\delta=-0.44, P<0.001)$, while there was evidence of less strain on the social network $(\delta=-0.21$, $P=0.07$ ) (Table 5).

When, rather than comparing the scores before and after the trial, we compared between groups, we saw very similar results, i.e. reduction in daily hassles, distress and strains in social network, and increase in self-efficacy and general satisfaction for the self-monitoring and self-managing patients compared with those who had received routine care. Although differences between groups A and B were small, there was a trend towards a further increase in general satisfaction by allowing the patients full self-management $(\delta=+0.30, P=0.14)$, and 
Table 4 Effect of patient self-monitoring of the International Normalized Ratio (INR) (group A)

\begin{tabular}{llll}
\hline & $\begin{array}{l}\text { Baseline }(n=47) \\
\text { mean (SD) }\end{array}$ & $\begin{array}{l}\text { Patient self-monitoring } \\
\text { of the INR (group A) }(n=47) \\
\text { mean (SD) }\end{array}$ & $\begin{array}{l}\text { Difference against } \\
\text { baseline (routine care) }(n=47) \\
\text { mean }(P)^{*}\end{array}$ \\
\hline Daily hassles & $1.61(0.57)$ & $1.52(0.50)$ & $-0.09(P=0.31)$ \\
Self-efficacy & $4.98(0.82)$ & $5.28(0.68)$ & $+0.31(P<0.01)$ \\
General treatment satisfaction & $5.11(0.82)$ & $5.30(0.71)$ & $+0.19(P=0.10)$ \\
Distress & $1.99(0.75)$ & $2.05(0.78)$ & $+0.06(P=0.56)$ \\
Strained social network & $1.44(0.55)$ & $1.42(0.50)$ & $-0.02(P=0.82)$ \\
\hline
\end{tabular}

Outcome of the questionnaire concerning five treatment-related topics. End-of-study evaluation of self-measurement group against baseline (conventional system of oral anticoagulant care through specialized anticoagulation clinics). Minimum score $=1$, maximum score $=6$. ${ }^{*}$ Paired samples $t$-test on the 47 patients with both baseline and end-of-study questionnaire available.

Table 5 Effect of full patient self-management (group B)

\begin{tabular}{llll}
\hline & $\begin{array}{l}\text { Baseline }(n=41) \\
\text { mean (SD) }\end{array}$ & $\begin{array}{l}\text { Patient self-management } \\
\text { (Group B) }(n=41) \\
\text { mean (SD) }\end{array}$ & $\begin{array}{l}\text { Difference against } \\
\text { baseline (routine care) }(n=41) \\
\text { mean }(P)^{*}\end{array}$ \\
\hline Daily hassles & $1.79(0.74)$ & $1.48(0.52)$ & $-0.31(P<0.01)$ \\
Self-efficacy & $5.20(0.76)$ & $5.52(0.72)$ & $+0.32(P=0.01)$ \\
General treatment satisfaction & $5.06(1.02)$ & $5.55(0.63)$ & $+0.49(P=0.01)$ \\
Distress & $2.16(0.79)$ & $1.72(0.59)$ & $-0.44(P<0.001)$ \\
Strained social network & $1.55(0.81)$ & $1.34(0.39)$ & $-0.21(P=0.07)$
\end{tabular}

Outcome of the questionnaire concerning five treatment-related topics, based on 32 items. End-of-study evaluation of self-management group against baseline (conventional system of oral anticoagulant care through specialized anticoagulation clinics). Minimum score $=1$, maximum score $=6$. ${ }^{*}$ Paired samples $t$-test on the 47 patients with both baseline and end-of-study questionnaire available.

especially a further significant decrease in the feelings of distress $(\delta=-0.50, P<0.001)$.

\section{Discussion}

Two major benefits from patient self-management of oral anticoagulant therapy have been put forward: an improvement in the quality of the therapy resulting in fewer complications, and an improvement in the quality of life through less imposition by regular blood sampling on the patients' way of life. It is evident from our study that patient self-management in the field of oral anticoagulant therapy does provide an improvement in patient quality of life compared with management by specialized anticoagulation clinics. This is borne out by an increased sense of general treatment satisfaction and a diminished perception of treatment-related distress or social strain.

From the baseline assessment it is also clear that overall the general treatment satisfaction indicated by the patients in the Dutch system of specialized anticoagulation clinics (score 5.11, SD 0.91) is higher than in Germany, where anticoagulation treatment is mostly done by family physicians (score $2.90, \mathrm{SD}$ 1.38) [4], although this difference may also be attributable to differences between patients in different countries. Younger patients report less general treatment satisfaction than older patients, which may be explained by the higher degree of intrusion into their lifestyle by the frequent blood sampling than is the case in older patients. From the discussions we had with patients it is clear that younger patients experience more problems in their professional (time off work through frequent visits to the anticoagulation clinics) and social lives caused by the frequent visits to anticoagulation clinics, and think themselves more restricted in their vacation plans. Younger patients also show a higher degree of irritation with daily hassles caused by the treatment, showing a need to compromise between the perceived potential side-effects of anticoagulant treatment and an active lifestyle. Over all age groups the perception of distress is more pronounced in women than in men $(P<0.05)$, and seems slightly higher in urban areas than in rural surroundings $(P<0.10)$, although this was not statistically significant.

In our study one group of patients underwent training for self-management of OAT but was afterwards randomized to continue with routine care to reflect the effect of increased patient awareness. These patients tended to report lower treatment satisfaction at the end of the study, which may be explained by the fact that they had agreed to participate in the study primarily in the hope of being randomized for selfmanagement and, being denied this opportunity, were then even less satisfied with the existing care system than they were beforehand. More significantly, they expressed a higher degree of distress and an increased strain on their social network after having received information about the treatment's effects, complications and influences thereon. We saw positive effects on QoL when we compared between groups, using this routine care group as a reference. Although this analysis is generally perceived as methodologically stronger than a before-after comparison, since it rules out regression-to-the-mean effects, it should be borne in mind that the end-of-study questionnaire results in those who were trained for self-management but subsequently received routine care may be heavily influenced 
by feelings of dissatisfaction with the study process, i.e. being denied self-management. Increased patient education may serve to improve the medical quality of the OAT, as we have seen in the part of the study dealing with this endpoint. In this group of patients time in INR target range was increased by almost 5\% [14], but perhaps at the cost of more distress and anxiety for the patient.

Giving the patients the opportunity to measure their own INR values at home relieves them from the burden of frequent visits to the anticoagulation clinics. In this patient group we noted an increase in general treatment satisfaction and the feeling of self-efficacy. There was little change in the perception of daily hassles, distress or strain on the social network against baseline; the increases that were noted in patients who also completed the training program but went back to the routine care system were not registered in these patients. Evidently, having the possibility to check the INR whenever they thought it necessary and the fact that they had some role in the treatment, compensated for the increased distress and anxiety caused by the increased patient awareness.

The largest changes in the scores of the five treatment-related topics were seen in the group of patients who were randomized for full self-management under supervision of the anticoagulation clinics. There was a clear increase in general treatment satisfaction and feeling of self-efficacy and - in contrast to the patients limited to self-monitoring - clear decreases in the perception of daily hassles, distress and strain on the social network. Having both the opportunity of INR measurements whenever necessary and the knowledge to adjust their medication seems to improve the confidence of the patients to deal with the different facets of their treatment. It has to be stressed that patients could rely on the services of the anticoagulation clinics at any time in case of problems or need for advice. In the part of the study dealing with the medical quality of the OAT, this group of patients also scored best as to the percentage of time within the INR target range [14].

The questionnaire used to evaluate the perceived quality of life of the patients has some drawbacks, but as it has been used by the few authors who have ventured into this terrain, it offers the possibility of making comparisons with earlier work. One of the weaknesses of the questionnaire is shown by the relatively low Cronbach $\alpha$ values (0.53-0.74), although both Sawicki et al. [4] and Cromheecke et al. [12], using the same questionnaire, reported somewhat higher Cronbach $\alpha$ values (0.64-0.82 and $0.70-0.83$, respectively).

From this study it is clear that patient self-management of oral anticoagulant therapy in motivated patients improves general treatment satisfaction, and decreases patients' perception of treatment-related daily hassles, distress and strain on their social network. The opportunity for home measurement of the INR also increases general treatment satisfaction but does not lessen the emotional impact of the treatment in the same way. Patient self-management of the oral anticoagulant therapy seems to offer the best treatment modality for motivated patients. This result is in line with recent research on self-management in other chronic medical conditions demonstrating the importance of involving patients in the care of their affliction [20,21]. However, it remains unclear whether self-management is an option for large numbers of patients, as we found only a minority of patients prepared to enter the study.

\section{Acknowledgements}

The study was set up at the instigation of the Dutch Federation of Anticoagulation Clinics (FNT) to evaluate the use of home PT monitoring devices and the capacity of the patients for selfmanagement of the OAT. The authors thank the members of the study teams at the Leiden Anticoagulation Clinic, Leiden (Dieuwke van de Plas, Kerst de Jong and Magda Koelewijn), and at the Oost-Gelderland Anticoagulation Clinic, Lichtenvoorde (Susanne Arentsen and Heidi ter Bogt), who together with the principal investigators were responsible for the training and practical and administrative follow-up of the patients. We also thank Roche Diagnostics for providing the necessary home PT monitoring equipment and financial support. They did not however, have any influence on the running of the study, the analysis or the writing of this paper. This study was partly financed through a grant from Roche Diagnostics (Almere, the Netherlands).

\section{References}

1 Poller E, Hirsh J, eds. Oral Anticoagulants. London: Arnold, 1996.

2 Breukink-Engbers WG. Monitoring therapy with anticoagulants in the Netherlands. Semin Thromb Hemost 1999; 25: 37-42.

3 Taborski U, Muller-Berghaus G. State-of-the-art patient self-management for control of oral anticoagulation. Semin Thromb Hemost 1999; 25: 43-7.

4 Sawicki PT. A structured teaching and self-management program for patients receiving oral anticoagulation: a randomized controlled trial. Working Group for the Study of Patient Self-Management of Oral Anticoagulation. JAMA 1999; 281: 145-50.

5 Ansell J, Holden A, Knapic N. Patient self-management of oral anticoagulation guided by capillary (fingerstick) whole blood prothrombin times. Arch Intern Med 1989; 149: 2509-11.

6 Ansell JE, Patel N, Ostrovsky D, Nozzolillo E, Peterson AM, Fish L. Long-term patient self-management of oral anticoagulation. Arch Intern Med 1995; 155: 2185-9.

7 Ansell JE, Hughes R. Evolving models of warfarin management: anticoagulation clinics, patient self-monitoring, and patient self-management. Am Heart J 1996; 132: 1095-100.

8 Ansell JE. Empowering patients to monitor and manage oral anticoagulation therapy. JAMA 1999; 281: 182-3.

9 Bernardo A. Optimizing long-term anticoagulation by patient selfmanagement? Z Kardiol 1998; 87 (Suppl. 4): 75-81.

10 Hasenkam JM, Kimose HH, Knudsen L, Gronnesby H, Halborg J, Christensen TD, Attermann J, Pilegaard HK. Self management of oral anticoagulant therapy after heart valve replacement. Eur J Cardiothorac Surg 1997; 11: 935-42.

11 Hasenkam JM, Knudsen L, Kimose HH, Gronnesby H, Attermann J, Andersen NT, Pilegaard HK. Practicability of patient self-testing of oral anticoagulant therapy by the international normalized ratio (INR) using a portable whole blood monitor. A pilot investigation. Thromb Res 1997; 85: 77-82.

12 Cromheecke ME, Levi M, Colly LP, de Mol BJM, Prins MH, Hutten BA, Mak R, Keyzers KCJ, Büller HR. Oral anticoagulation self- 
management and management by a specialist anticoagulation clinic: a randomised cross-over comparison. Lancet 2000; 356: 97-102.

13 Kulinna W, Ney D, Wenzel T, Heene DL, Harenberg J. The effect of self-monitoring the INR on quality of anticoagulation and quality of life. Semin Thromb Hemost 1999; 25: 123-6.

14 Gadisseur APA, Breukink-Engbers WGM, van der Meer FJM, van den Besselaar AMHP, Sturk A, Rosendaal FR. Comparison of the quality of oral anticoagulant therapy through patient self-management versus management by specialized anticoagulation clinics in the Netherlands: a randomized clinical trial. Arch Intern Med 2003; 163: 2639-46.

15 Wilson IB, Cleary PD. Linking clinical variables with health-related quality of life. A conceptual model of patient outcomes. JAMA 1995; 273: 59-65.

16 Kaptein AA, Creer TL, eds. Respiratory Disorders and Behavioral Medicine. London: Martin Dunitz, 2002.
17 Gonder-Frederick LA, Cox DJ, Ritterband LM. Diabetes and behavioral medicine: the second decade. J Cons Clin Psychol 2002; 70: 611-25.

18 Juniper EF, Guyatt GH, Streiner DL, King DR. Clinical impact versus factor analysis for quality of life questionnaire construction. $J$ Clin Epidemiol 1997; 50: 233-8.

19 Schwarzer R, ed. Self-Efficacy: Thought Control of Action. Washington DC: Hemisphere, 1992.

20 Nicassio PM, Smith TW, eds. Managing Chronic Illness, A Biopsychosocial Perspective. Washington DC: American Psychological Association, 1995.

21 Smith TW, Kendall PC, Keefe FJ. Behavioral medicine and clinical health psychology, special issue. J Consult Clin Psychol 2002; 70: $459-62$. 